\title{
ULTIMATE SPECTRAL EFFICIENCY OF INFORMATION TRANSMISSION OF FIBRE AMPLIFIERS IN WDM SYSTEMS
}

\author{
M.A. Khodasevich ${ }^{\mathrm{a}}$, G.V. Sinitsyn ${ }^{\mathrm{a}}$, Yu.A. Varaksa ${ }^{\mathrm{a}}$, and A.S. Yasukevich ${ }^{\mathrm{b}}$ \\ a Institute of Physics, National Academy of Sciences of Belarus, Kuprevich Str. 1, 220141 Minsk, Republic of Belarus \\ E-mail: mike@optoinform.bas-net.by \\ b International Laser Centre, BNTU, F. Skaryna Ave. 65, 220013 Minsk, Republic of Belarus \\ E-mail: anatol@ilc.by
}

Received 29 October 2004

\begin{abstract}
Numerical modelling of ultimate spectral efficiency of information transmission in wavelength-division multiplexing (WDM) systems is carried out for the case when the noise of optical fibre amplifiers determines the system capacity. The number-state model is used for finding spectral efficiency of communication lines with erbium-doped (EDFA) and chromiumdoped fibre amplifiers (CDFA). The results obtained show that spectral efficiency of CDFA exceeds that of EDFA throughout the conventional band and approaches the "quantum limit" in a window of transparency of advanced fibres in the high pump power limit. The ultimate capacity of communication systems with CDFA is estimated to be about $300 \mathrm{Tbit} / \mathrm{s}$.
\end{abstract}

Keywords: erbium-doped fibre amplifier, spectral efficiency, ultimate capacity

PACS: 42.60.Da, 42.60.Lh, 42.81.Wg

\section{Introduction}

The steady growth of capacity of optical communication systems is the main trend of their development. It is achieved by both expansion of a passband and increase of a bit rate. Er-doped fibre amplifiers (EDFA) which are the today most frequently used optical fibre amplifiers have the bandwidth up to $80 \mathrm{~nm}$ in systems with split conventional and longwavelength bands. New types of optical fibres with the reduced hydroxyl group absorption need optical amplifiers with the spectral range from 1.3 to $1.6 \mu \mathrm{m}$. Crdoped fibre amplifiers (CDFA) are one of the possible choices which meet this requirement. In the present paper we compare ultimate high-rate characteristics of EDFA and CDFA in wavelength-division multiplexing (WDM) systems within the framework of the numberstate model [1].

\section{Model}

The rate of information transmission in recent communication systems is limited mainly by noise of amplifiers, nonlinear effects, and dispersion in a fibre. Influence of the last two factors may be reduced by increasing the cross-section of a fibre and application of fibres with dispersion management or photonic crystal fibres, for example. In this case the capacity of the communication line is determined by the noise of optical fibre amplifiers only. Therefore, for finding ultimate high-rate characteristics of optical communication systems the idealized amplifier should be considered which is free from nonlinearity and dispersion. For EDFA the estimation of fundamental limits for spectral efficiency of information transmission was carried out with the help of entropy analysis [2]. There the approach of early contributions $[3,4]$ has been applied which implies that the quantum nature of data carriers in the communication channel is taken into account only in the case of a large signal-to-noise ratio in the communication system. Furthermore, noise of the amplifier has not been separated from the input noise.

In this paper we investigate the ultimate spectral efficiency which is the maximum achievable rate of information transmission per unit passband. There is a lot of different methods for finding the ultimate characteristics of linear communication channels [1,3-10]. A brief review of basic concepts and models is presented in [11], more detailed analysis can be found in [12].

We use the number-state model which is the most adequate one for our case. It implies that the infor- 
mation is conveyed by an amount of quanta in different modes of electromagnetic field and correctly determines the ultimate capacity of the linear optical communication channel for any signal-to-noise ratio. The simple thermodynamic derivation [1] gives the following dependence for the capacity of a broadband communication channel:

$$
C=\frac{\pi^{2} k T}{3 h \ln 2}\left(\sqrt{1+\frac{6 h P_{\mathrm{s}}}{\pi^{2}(k T)^{2}}}-1\right),
$$

where $k$ is the Boltzmann constant, $T$ is an environment temperature, $h$ is the Planck constant, and $P_{\mathrm{s}}$ is the signal power. At a small signal-to-noise ratio Eq. (1) turns into Shannon's expression [5]

$$
C_{\text {class }}=\frac{1}{\ln 2} \frac{P_{\mathrm{s}}}{k T}
$$

for a broadband channel with additive Gaussian noise.

Let us consider the peculiarities of application of the number-state model for optical fibre amplifiers in WDM systems. We study the idealized system which is free from nonlinearity. The cross-talk between separate WDM channels can be neglected. Hence, they can be considered independently as narrow-band (quasi-monochromatic) communication channels with the bandwidth being much smaller than the central frequency. The possibility to determine the spectral efficiency (often called the information-rate density $I D$ ) regardless of the amplifier bandwidth is the essential advantage of this approach [11]:

$$
\begin{aligned}
I D= & \log _{2}\left[1+\frac{S N R(0)}{F_{0}}\right] \\
& +\frac{S N R(0)}{F_{0}} \log _{2}\left[1+\frac{F_{0}}{S N R(0)}\right],
\end{aligned}
$$

where $F_{0}$ stands for the noise figure of the amplifier. $S N R(0)$ is the input signal-to-noise ratio.

\section{Results}

In the general case the spectral efficiency of information transmission of a fibre amplifier depends on gain, pump conditions, absorption and emission crosssections at pump and signal wavelengths, and the input signal-to-noise ratio. The situation is considerably simpler for the high pump power limit when the noise figure does not depend on pump conditions and gain. The noise figure becomes as small as $3 \mathrm{~dB}$ (the so-called "quantum limit" [13]) in the high pump power limit for Er-doped preamplifiers and final amplifiers that are

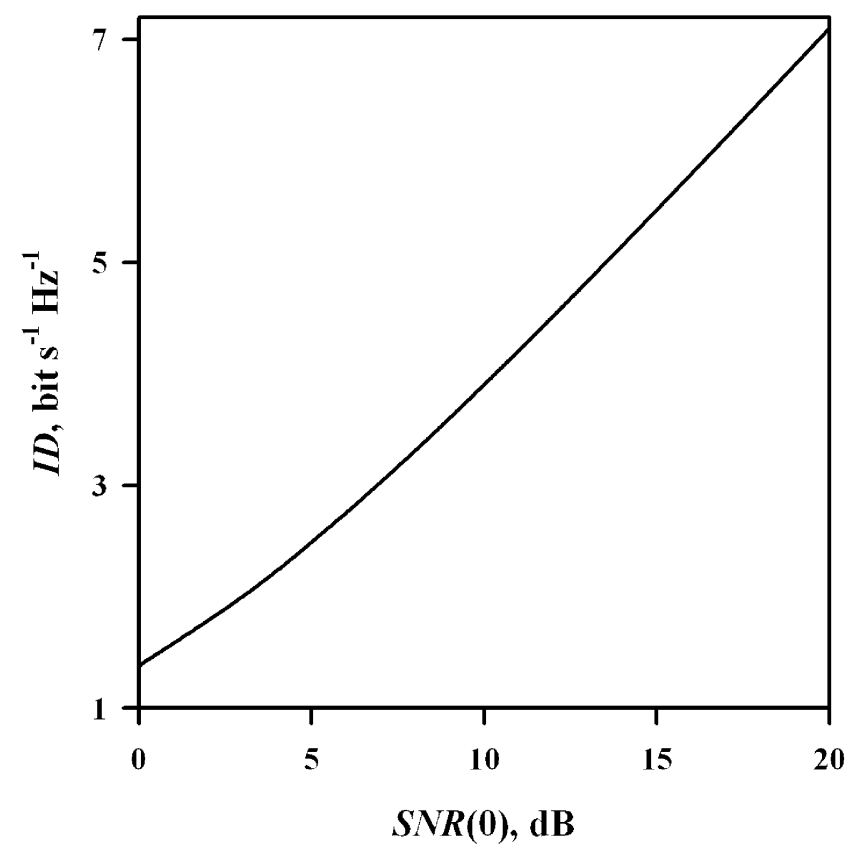

Fig. 1. Ultimate spectral efficiency of information transmission of amplifiers that are pumped as three- or four-level systems in the high pump power limit.

pumped at $980 \mathrm{~nm}$ and for Cr-doped amplifiers that are pumped in the spectral range of $460-960 \mathrm{~nm}$. The ultimate efficiency depends in this case on the input signalto-noise ratio only and slightly exceeds $7 \mathrm{bit} \cdot \mathrm{s}^{-1} \cdot \mathrm{Hz}^{-1}$ for $S N R(0)=20 \mathrm{~dB}$ (see Fig. 1).

For amplifiers that are pumped as quasi-two-level systems (booster amplifiers) the minimum noise figure $F_{0}^{\min }$ in the high gain limit depends on absorption $\sigma_{\mathrm{a}}$ and emission $\sigma_{\mathrm{e}}$ cross-sections at signal $\lambda$ and pump $\lambda_{\mathrm{p}}$ wavelengths [13]:

$$
F_{0}^{\min }=2\left[1-\frac{\sigma_{\mathrm{e}}\left(\lambda_{\mathrm{p}}\right) \sigma_{\mathrm{a}}(\lambda)}{\sigma_{\mathrm{a}}\left(\lambda_{\mathrm{p}}\right) \sigma_{\mathrm{e}}(\lambda)}\right]^{-1} .
$$

In this case the minimum achievable noise figure is always greater than $3 \mathrm{~dB}$. For our calculations of spectral efficiency the absorption and emission spectra [13] of typical alumino-germanosilicate Er-doped fibre have been used. The obtained results are shown in Fig. 2.

For Cr-doped silica-based fibre the absorption and fluorescence spectra as well as fibre parameters are presented in [14]. In order to use these data, Eq. (3) should be converted to the following form with the help of the Fuchtbauer-Ladenburg equation [15]:

$$
F_{0}^{\min }=2\left[1-\frac{\lambda_{\mathrm{p}}^{4}}{\lambda^{4}} \frac{I\left(\lambda_{\mathrm{p}}\right.}{I(\lambda)} \frac{\alpha(\lambda)}{\alpha\left(\lambda_{\mathrm{p}}\right)}\right]^{-1},
$$

where $\alpha$ is absorption in $\mathrm{dB} / \mathrm{m}$ and $I$ is fluorescence intensity in a.u. 


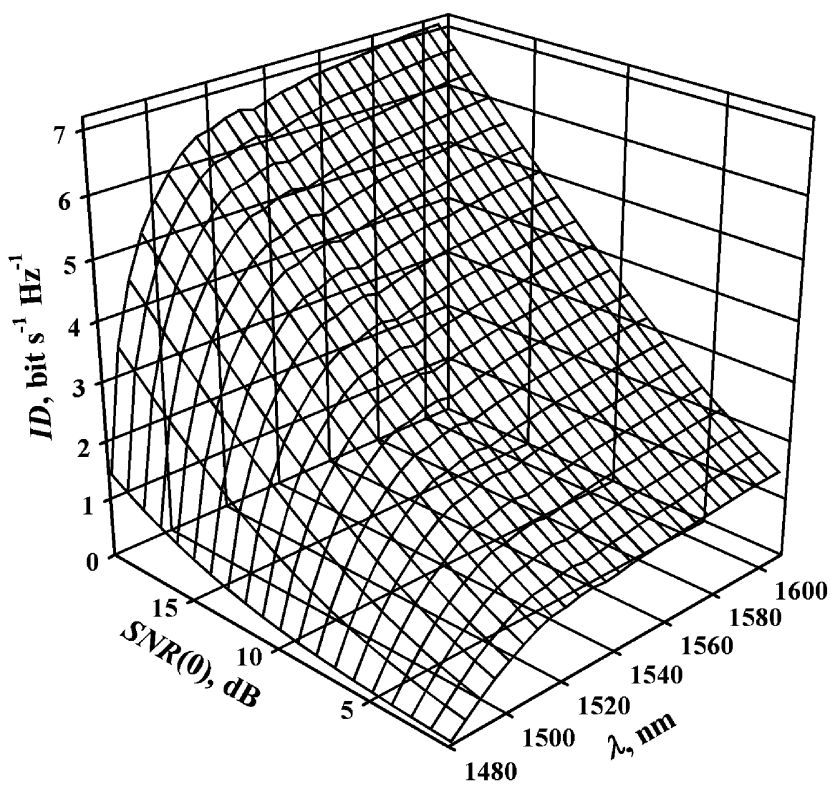

Fig. 2. Ultimate spectral efficiency of information transmission of EDFA in the high pump power limit at $1480 \mathrm{~nm}$.

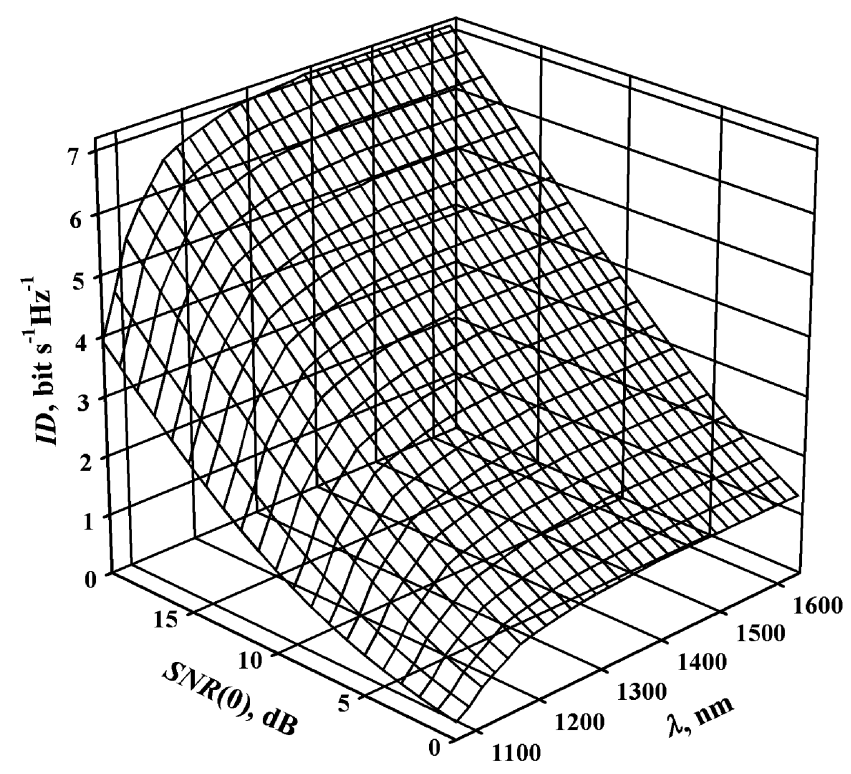

Fig. 3. Ultimate spectral efficiency of information transmission of CDFA in the high pump power limit at $1060 \mathrm{~nm}$.

The ultimate spectral efficiency of CDFA that is pumped at $1060 \mathrm{~nm}$ is derived from Eqs. (2) and (4) and presented in Fig. 3. In this case $\sigma_{\mathrm{e}}\left(\lambda_{\mathrm{p}}\right) \neq 0$ but the minimum noise figure of CDFA approaches the "quantum limit" in the spectral range of 1.3-1.6 $\mu \mathrm{m}$. It gives spectral efficiency of CDFA as high as $7 \mathrm{bit} \cdot \mathrm{s}^{-1} \cdot \mathrm{Hz}^{-1}$ for $S N R(0)=20 \mathrm{~dB}$ all over the window of transparency of advanced fibres. Moreover, one can see that the spectral efficiency of CDFA exceeds that of EDFA throughout the conventional band. Hence, a
Cr-doped fibre booster amplifier not only has a wider passband [14] in comparison with EDFA but its ultimate spectral efficiency is slightly greater in the high pump power limit. The total capacity of a communication system with CDFA can be about $300 \mathrm{Tbit} / \mathrm{s}$ for $S N R(0)=20 \mathrm{~dB}$ that is seven times more than the total capacity of a system with EDFA in the conventional band $(\approx 40 \mathrm{Tbit} / \mathrm{s})$.

It should be noted that current commercial DWDM systems with $100 \mathrm{GHz}$ channel spacing and $40 \mathrm{Gbit} / \mathrm{s}$ bit rate have the spectral efficiency of only $0.4 \mathrm{bit} \cdot \mathrm{s}^{-1} \cdot \mathrm{Hz}^{-1}$. The calculated above efficiencies of information transmission require some nonbinary encoding technique because the efficiency for any system using on-off keying cannot exceed $1 \mathrm{bit} \cdot \mathrm{s}^{-1} \cdot \mathrm{Hz}^{-1}$. It may be, for example, multilevel phase or intensity modulation. Furthermore, the values obtained significantly exceed the ultimate spectral efficiency (3 bit $\cdot \mathrm{s}^{-1} \cdot \mathrm{Hz}^{-1}$ ) of nonlinear optical communication systems assuming coherent detection [16]. Thus, the obtained results demonstrate a great potential of broadband linear optical communication systems with advanced encoding techniques.

\section{Conclusion}

On the base of the number-state model we compared ultimate spectral efficiencies of information transmission of erbium-doped and chromium-doped fibre amplifiers. It was established that spectral efficiency of CDFA exceeds that of EDFA throughout the conventional band and approaches the "quantum limit" in the window of transparency $(1.3-1.6 \mu \mathrm{m})$ of advanced fibres in the high pump power limit. The total capacity of communication systems with CDFA under these conditions can be about $300 \mathrm{Tbit} / \mathrm{s}$ that is seven times more than the total capacity of a system with EDFA in the conventional band $(\approx 40 \mathrm{Tbit} / \mathrm{s})$.

\section{References}

[1] D.S. Lebedev and L.B. Levitin, Information transmission by electromagnetic field, Inf. Control. 9, 1-22 (1966).

[2] E. Desurvire, Fundamental information-density limits in optically amplified transmission: An entropy analysis, Opt. Lett. 25(10), 701-703 (2000). 
[3] T.E. Stern, Some quantum effects in information channels, IRE Trans. Inf. Theory IT-6(4), 435-440 (1960).

[4] J.P. Gordon, Quantum effects in communication systems, IRE Proc. 50(9), 1898-1908 (1962).

[5] C.E. Shannon, Communication in the presence of noise, IRE Proc. 37(1), 10-21 (1949).

[6] J.B. Pendry, Quantum limits on the flow of information and entropy, J. Phys. A 16, 2161-2171 (1983).

[7] J.B. Bekenstein, Entropy content and information flow in systems with limited energy, Phys. Rev. D 30(8), 1669-1679 (1984).

[8] H.J. Bremermann, Minimum energy requirements of information transfer and computing, Int. J. Theor. Phys. 21, 203-217 (1982).

[9] M. Shiffer, Quantum limit for information transmission, Phys. Rev. A 43, 5337-5343 (1991).

[10] D. Gabor, Communication theory and physics, Philos. Mag. 41(322), 116-187 (1950).
[11] G.V. Sinitsyn and M.A. Khodasevich, Entropic analysis of the information rate density of broadband active fiber-optic communication links, Opt. Spektrosk. 97(3), 464-467 (2004).

[12] C.M. Caves and P.D. Drummond, Quantum limits on bosonic communication rates, Rev. Mod. Phys. 66(2), 481-537 (1994).

[13] E. Desurvire, Erbium-Doped Fiber Amplifiers (Wiley, New York, 1994).

[14] B. Dussardier, V. Felice, G. Monnom et al., in: Lasers and Electro-Optics Europe, Conference Digest (Nice, France, 2000) CWF35.

[15] A.S. Yasukevich, V.G. Shcherbitskii, V.E. Kisel et al., Integral method of reciprocity in the spectroscopy of laser crystals with impurity centers, J. Appl. Spectrosc. 71(2), 202-208 (2004).

[16] P.P. Mitra and J.B. Stark, Nonlinear limits to the information capacity of optical fibre communications, Nature 411, 1027-1030 (2001).

\title{
MAKSIMALUS PLUOŠTINIŲ STIPRINTUVŲ INFORMACIJOS PERDAVIMO SPEKTRINIS NAŠUMAS MULTIPLEKSINĖSE SISTEMOSE
}

\author{
M.A. Khodasevich ${ }^{\text {a }}$, G.V. Sinitsyn ${ }^{\text {a }}$, Yu.A. Varaksa ${ }^{\text {a }}$, A.S. Yasukevich ${ }^{\mathrm{b}}$ \\ ${ }^{\text {a } F i z i k o s ~ i n s t i t u t a s, ~ M i n s k a s, ~ B a l t a r u s i j a ~}$ \\ b Tarptautinis lazeriu centras, Minskas, Baltarusija
}

\section{Santrauka}

Skaitmeniškai sumodeliuotas informacijos perdavimo multipleksinèse (WDM) sistemose maksimalus spektrinis našumas, kai optinis pluoštinis stiprintuvas nulemia sistemos pralaidumą. Nagrinètos ryšių linijos, i kurias ịjungti pluoštiniai stiprintuvai su chromo arba erbio priemaišomis. Rasta, kad ịprastinejje juostoje stiprintuvų su chromo priemaišomis spektrinis našumas yra didesnis už stiprintuvų su erbio priemaišomis spektrini našumą, o taikant aukštos galios kaupinima jis priarteja prie taip vadinamosios kvantinès ribos. Minètųu sistemų maksimalus pralaidumas įvertintas $300 \mathrm{Tbit} / \mathrm{s}$. 